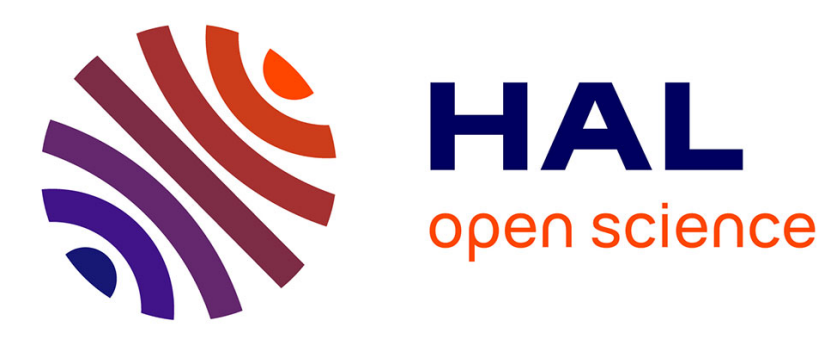

\title{
Does prostate cancer aggressiveness change with increasing age?
}

\author{
Michael Froehner, Matt T. Rosenberg
}

\section{To cite this version:}

Michael Froehner, Matt T. Rosenberg. Does prostate cancer aggressiveness change with increasing age?. International Journal of Clinical Practice, 2011, 65 (5), pp.521. 10.1111/j.17421241.2011.02661.x . hal-00631702

\section{HAL Id: hal-00631702 \\ https://hal.science/hal-00631702}

Submitted on 13 Oct 2011

HAL is a multi-disciplinary open access archive for the deposit and dissemination of scientific research documents, whether they are published or not. The documents may come from teaching and research institutions in France or abroad, or from public or private research centers.
L'archive ouverte pluridisciplinaire HAL, est destinée au dépôt et à la diffusion de documents scientifiques de niveau recherche, publiés ou non, émanant des établissements d'enseignement et de recherche français ou étrangers, des laboratoires publics ou privés. 


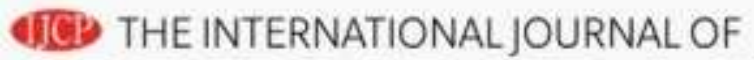 CLINICAL PRACTICE}

\section{Does prostate cancer aggressiveness change with} increasing age?

\begin{tabular}{|r|l|}
\hline Journal: & International Journal of Clinical Practice \\
\hline Manuscript ID: & IJCP-09-10-0518.R1 \\
\hline Wiley - Manuscript type: & Perspective \\
\hline Specialty area: & \\
\hline \multicolumn{3}{c}{ SCHOLARONE } \\
\\
\multicolumn{3}{c}{ Manuscripts $^{m}$} \\
\end{tabular}


Does prostate cancer aggressiveness change with increasing age?

Revised manuscript \# IJCP-09-10-0518

Michael Froehner ${ }^{1}$, Matt T. Rosenberg ${ }^{2}$

${ }^{1}$ Department of Urology,

University Hospital "Carl Gustav Carus",

Technical University of Dresden,

Fetscherstrasse 74,

D-01307 Dresden, Germany.

Phone: $\quad+49-3514587462$

Fax: $\quad+49-3514584333$

E-mail: Michael.Froehner@uniklinikum-dresden.de

${ }^{2}$ Department of Family Medicine,

Allegiance Health Systems

Mid-Michigan Health Centers,

214 N. West Ave,

Jackson, MI, 49201, USA.

Phone: $\quad+1-5177849189$

Fax: $\quad+1-5177849657$

Email: mattoren@yahoo.com

\section{Disclosures:}

In the past 3 years, Dr. Rosenberg has been a member of a Speakers Bureau and served as consultant to Abbott Laboratories, Allergan, Inc, Astellas Pharma US, Inc, GlaxoSmithKline, Ortho-McNeil-Janssen Pharmaceuticals, Inc, SanofiAventis US, Schering-Plough, and Watson Pharmaceuticals, Inc. He has also been a member of a Speakers Bureau for Forest Laboratories, Inc, Novartis AG, and Pfizer Inc, and served as consultant to Hoffman-La Roche, Inc.

In the past 3 years, Dr. Froehner received lecture honoraries or meeting participation support from the following companies: AstraZeneca, GlaxoSmithKline, SanolfiAventis, Apogepha, Pfizer, Novartis and Bayer.

Key words: prostate cancer, survival, age, biology, radical prostatectomy, active surveillance, external beam radiotherapy, randomized trials.

Word count: 1483, summary: 107,22 references. 


\section{Summary}

With the continuously increasing life expectancy in many parts of the world, prostate cancer is likely to become an increasingly important health problem. As life expectancy in men increase, not only are they more likely to be diagnosed with prostate cancer but also to live longer with the disease resulting in a risk of experiencing tumor progression and of eventually dying from the disease. It is unclear whether prostate cancers effecting younger individuals have a different biology compared with those occurring in the elderly. Considering the challenges of demographic change, it may be important to answer this question in order to tailor optimal individualized treatment strategies. 
In the United States and many European countries, prostate cancer is the most common non-dermatological malignancy in males [1]. Old age is a well-established risk factor for prostate cancer. More than half of incident prostate cancer cases and more than $90 \%$ of deaths from prostate cancer occur in men aged 65 years or older [2]. Since the life expectancy continues to rise in most developed countries due to decreasing old-age mortality [3], men will be increasingly likely to live long enough to develop symptomatic or even fatal prostate cancer. Prostate cancer in the elderly therefore represents an increasingly important health problem. The relationship between age and prostate cancer biology is, however, still subject to controversies $[4,5]$.

\section{Data from randomized trials}

In the European Randomized Study of Screening for Prostate Cancer (ERSPC), prostate-specific-antigen-(PSA)-based screening was found to reduce the mortality from prostate cancer for the entire study population by $20 \%$ [6]. This effect was, however, not demonstrable for study participants aged 70-74 years (the oldest age group included in this trial), among whom the rate ratio for death from prostate cancer in the screening arm was 1.26 (95\% confidence interval: $0.80-1.99)$ compared to no screening [6]. These data suggests that men may not benefit from prostate cancer screening beyond their $70^{\text {th }}$ year of life.

In the only currently available randomized trial comparing radical prostatectomy with watchful waiting in men with clinically diagnosed prostate cancer, there were no detectable differences in disease-specific and overall survival rates between both treatment arms in the subset of men aged 65 years or older. Surprisingly, patients aged 65 years or older assigned to the watchful waiting arm were less likely to 
develop metastases or to die from prostate cancer, compared with their younger conservatively treated counterparts [7]. Concerning disease-specific survival and metastatic progression, the survival curves in men aged 65 years or older whether of watchful waiting or surgery were very similar to that in younger ones assigned to radical prostatectomy.

Subgroup analysis showed that the benefit of the radical prostatectomy was limited to younger men and that watchful waiting resulted in worse outcomes (concerning

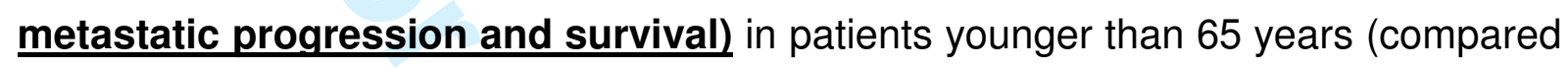
with the radical prostatectomy arm in this younger subgroup and to both treatment arms in men aged 65 or more years). The authors caution that the study was not designed to look at specific age groups and note that they have no data to judge biologic relevance of this age threshold. They further noted that the effect was not statistically significant. However, they did hypothesize that if the patients had reached an advanced age, potentially lethal tumors were more likely of already having metastasized and therefore being incurable [7]. Compared with younger patients, in those aged 65 or more years undergoing watchful waiting, there was, however, a decreased rate of metastatic and eventually fatal progression [7], calling this hypothesis into question.

\section{Results of observational studies}

In a series of 412 patients with metastatic prostate cancer, young age was an independent adverse predictor of disease progression and mortality [8] suggesting a faster progression of metastatic disease in younger patients. If confirmed in different samples, this finding could be an alternative explanation of the restriction of the treatment effect to younger men in the cited Scandinavian randomized trial [7]. There 
are, however, also data showing poorer survival in elderly men with prostate cancer. In a recent study, the outcome of metastatic prostate cancer was scarcely modified by age, whereas in locally advanced non-metastatic (cT4NOM0) disease there was a higher survival rate in younger men [9]. This finding led the authors to conclude that surgery offers better outcomes in this age group and should be offered as part of multimodal therapy. No theory was offered as to why a benefit was seen [9]. In another recently published very large study, higher age was associated with poorer prostate cancer-specific survival in univariate but not in multivariate analysis (after controlling for treatment modality and disease risk) [10].

In patients from the pre-PSA era, age was not associated with prostate cancerspecific survival neither after radical prostatectomy nor after external beam radiotherapy or with expectant management [11]. Also in a recently published series of conservatively treated prostate cancer patients aged 65 years or older diagnosed between 1992 and 2002, the probability to succumb to their cancer within 10 years did narrowly not differ after subdivision into age groups [12]. Another study revealed a higher progression rate and a lower disease-specific survival among patients who underwent radical prostatectomy at an age of more than 70 years, compared with their younger counterparts in univariate but not in multivariate analysis (after controlling for the less favorable tumor-related risk profile in the elderly cohort) [5]. Among high-risk patients (those with a Gleason score of 8-10 or positive lymph nodes), impaired disease-specific survival rates were observed in elderly men, whereas there were no such differences in the lower risk subgroups [13]. Similar observations were made by d'Amico and co-workers after external beam radiotherapy for clinically localized prostate cancer where older age was associated with a significantly worse prostate cancer-specific survival [14]. 
To further add to the controversy, several studies demonstrated an adverse impact of higher age on prostate cancer progression rates after radical prostatectomy. After radical prostatectomy, a decreased progression rate in men younger than 40 years has been reported [15] as well as higher biochemical tumor control rates in men younger than 50 years [16], aged 60 years or younger $[\underline{17,18}]$ and aged 70 years or younger [19], respectively. Richstone and co-workers observed a higher proportion of adverse tumor-related prognostic factors (Gleason score, clinical and pathological stages) in men aged 70 years or older compared with their younger counterparts but no differences in biochemical disease-free and cancer-specific survival rates [이. Less favorable tumor-related prognostic factors but no differences in systemic progression and prostate cancer-specific survival rates were made in another large study [21]. In two series with narrowly 5.000 patients each tumors with adverse prognostic criteria were also more frequent in elderly men [5,21], whereas smaller studies did not reveal such differences $[13,18]$.

\section{Explanations for the reported associations between age and prostate cancer} outcome

From the available data, identifying a consistent pattern of interaction between age and prostate cancer aggressiveness is difficult. It is relatively well documented that there is an increasing proportion of adverse tumor-related prognostic factors with increasing age $[5, \underline{10,20-22}]$ and a majority of studies seem to suggest an adverse impact of higher age on prostate cancer-related outcome $[5,9, \underline{10,13-19}$. However, there is also some evidence for the opposite $[7,8]$. With the currently available data, it is not possible to explain the surprising lack of efficacy of radical prostatectomy versus watchful waiting in men aged 65 years or older in the Scandinavian 
randomized trial comparing radical prostatectomy with watchful waiting [7]. The different distribution of risk factors for disease progression and mortality between older and younger patients in some studies $[5, \underline{20-22}]$ might in parts be caused by a greater probability of elderly patients with factors suggesting aggressive disease (higher PSA value, larger tumor volume, higher Gleason score) being recommended to undergo immediate active treatment (surgery or radiotherapy) instead of active surveillance or palliative care. Such selection effect might result in an enrichment of higher risk tumors in elderly surgical or radiotherapeutic samples and, conversely, of lower risk cancers in younger conservatively treated cohorts and may not be completely controlled for during statistical analysis. PSA-based prostate cancer screening that identifies tumors with a particularly favorable prognosis may create another bias creating an improved outcome in younger men. Whether there are in addition the described confounding factors intrinsic biological (tumor- or host-related) age-related differences is yet unknown [21].

\section{Future studies}

To obtain reliable answers to the question whether increasing age modifies the aggressiveness of early prostate cancer, more information from randomized trials would be desirable. Appropriately designed studies could investigate such issues as whether tumor progression rates are actually lower in elderly conservatively treated patients as the Scandinavian randomized trial [7] suggested or whether there are subgroups who are at a high risk of progression and could benefit from immediate curative treatment also at an advanced age. Even randomized trials, however, might be affected by a selection bias caused by an earlier detection of cancers by screening in younger men and a preference of aggressive treatment in elderly 
patients with an adverse tumor-related risk profile. Despite randomization, such kind of selection might result in an enrichment of young low risk cases and simultaneously elderly high risk cases making comparisons between age groups difficult to interpret.

\section{Conclusion}

At present, identifying a consistent pattern of interaction between age and prostate cancer aggressiveness is difficult. Selection may have confounded particularly nonrandomized studies. Randomized trials comparing competing treatment options in elderly men with early prostate cancer that are adequately powered to enable meaningful subgroup analyses to investigate the relationship between age and prostate cancer biology. 


\section{References:}

1 Jemal A, Siegel R, Xu J et al. Cancer Statistics, 2010. CA Cancer J Clin 2010; 60: 277-300.

2 Altekruse SF, Kosary CL, Krapcho M et al. SEER Cancer Statistics Review, 19752007, National Cancer Institute. Bethesda, MD, based on November 2009 SEER data submission, posted to the SEER web site, 2010. Available from: http://seer.cancer.gov/csr/1975_2007/ [accessed January 19, 2011].

3 Christensen K, Doblhammer G, Rau R et al. Ageing populations: the challenges ahead. Lancet 2009; 374: 1196-208.

4 Sun L, Caire AA, Robertson CN et al. Men older than 70 years have higher risk prostate cancer and poorer survival in the early and late prostate specific antigen eras. J Urol 2009 182: 2242-8.

5 Froehner M. Age and prostate cancer survival. JAMA 2010; 303: 33-4.

6 Schröder FH, Hugosson J, Roobol MJ et al. Screening and prostate-cancer mortality in a randomized European study. N Engl J Med 2009; 360: 1320-8.

7 Bill-Axelson A, Holmberg L, Filén F et al. Radical prostatectomy versus watchful waiting in localized prostate cancer: the Scandinavian prostate cancer group-4 randomized trial. J Natl Cancer Inst 2008; 100: 1144-54.

8 Nayyar R, Sharma N, Gupta NP. Prognostic factors affecting progression and survival in metastatic prostate cancer. Urol Int 2010; 84: 159-63.

9 Hsiao W, Moses KA, Goodman M, et al. Stage IV Prostate Cancer: Survival Differences in Clinical T4, Nodal and Metastatic Disease. J Urol 2010; 184: 512-18 17.

10 Bechis SK, Carroll PR, Cooperberg MR: Impact of age at diagnosis on prostate cancer treatment and survival. $J$ Clin Oncol 2010 [Epub ahead of printl.

11 Barry MJ, Albertsen PC, Bagshaw MA et al. Outcomes for men with clinically nonmetastatic prostate carcinoma managed with radical prostatectomy, external beam radiotherapy, or expectant management: a retrospective analysis. Cancer 2001; 91: 2302-14.

12 Lu-Yao GL, Albertsen PC, Moore DF et al. Outcomes of localized prostate cancer following conservative management. JAMA 2009; 302: 1202-9.

13 Froehner $M$, Koch $\mathrm{R}$, Litz RJ et al. Survival analysis in men undergoing radical prostatectomy at an age of 70 years or older. Urol Oncol 2010; 28: 628-34.

14 D'Amico AV, Cote $\mathrm{K}$, Loffredo $\mathrm{M}$ et al. Advanced age at diagnosis is an independent predictor of time to death from prostate carcinoma for patients 
undergoing external beam radiation therapy for clinically localized prostate carcinoma. Cancer 2003; 97: 56-62.

15 Loeb S, Hernandez DJ, Mangold LA et al. Progression after radical prostatectomy for men in their thirties compared to older men. BJU Int 2008; 101: 1503-6.

16 Khan MA, Han M, Partin AW et al. Long-term cancer control of radical prostatectomy in men younger than 50 years of age: update 2003. Urology 2003; 62: 86-91.

17 Jayachandran J, Bañez LL, Levy DE et al. Risk stratification for biochemical recurrence in men with positive surgical margins or extracapsular disease after radical prostatectomy: results from the SEARCH database. J Urol 2008; 179: 1791-6.

18 Kane CJ, Im R, Amling CL et al. Outcomes after radical prostatectomy among men who are candidates for active surveillance: Results from the SEARCH database. Urology 2010 [Epub ahead of print].

19 Öbek C, Lai S, Sadek S et al. Age as a prognostic factor for disease recurrence after radical prostatectomy. Urology 1999; 54: 533-8.

20 Richstone L, Bianco FJ, Shah HH et al. Radical prostatectomy in men aged >or $=70$ years: effect of age on upgrading, upstaging, and the accuracy of a preoperative nomogram. BJU Int 2008; 101: 541-6.

21 Siddiqui SA, Sengupta S, Slezak JM et al. Impact of patient age at treatment on outcome following radical retropubic prostatectomy for prostate cancer. J Urol 2006; 175: 952-7.

$\underline{22}$ Borek $\mathrm{D}$, Butcher $\mathrm{D}$, Hassanein $\mathrm{K}$ et al. Relationship of age to histologic grade in prostate cancer. Prostate 1990; 16: 305-11. 


\section{Key messages}

With the currently available data, it is difficult to identify a consistent pattern of interaction between age and prostate cancer aggressiveness.

Altogether, a majority of studies seem to suggest an adverse impact of higher age on prostate cancer-related outcome, there is, however, also some evidence for the opposite.

Currently, it is not possible to explain the disturbing lack of efficacy of radical prostatectomy versus watchful waiting in men aged 65 years or older in the Scandinavian randomized trial comparing radical prostatectomy with watchful waiting sufficiently. 